\title{
BUILDING A NEW ACADEMIC FIELD: THE INSTITUTIONALISATION OF TAIWAN STUDIES IN EUROPE
}

\author{
Hardina Ohlendorf * \\ Mahidol University International College, Salaya, \\ Phutthamonthon District, Nakhon Pathom, 73170 Thailand \\ email: hardina.ohl@mahidol.ac.th
}

Published online: 15 July 2017

To cite this article: Ohlendorf, H. 2017. Building a new academic field: The institutionalisation of Taiwan Studies in Europe. International Journal of Asia Pacific Studies 13 (2): 115-140, https://doi.org/10.21315/ijaps2017.13.2.6

To link to this article: https://doi.org/10.21315/ijaps2017.13.2.6

\begin{abstract}
The emergence of Taiwan Studies as a new area study in Europe is an intriguing phenomenon. It started more or less "from scratch" at a time when the area studies model was seriously challenged in academic debates. Since then the field has rapidly expanded in Europe. This paper seeks to analyse the factors that have facilitated the successful institutionalisation of academic Taiwan Studies in a region that otherwise does not have close relations with Taiwan. It argues that financial overtures from Taiwan have found fertile ground in Europe, which has to do with the distinct Asian Studies tradition on the continent, a major restructuring of the university field since the 1990s, and the specific historical circumstances of Taiwan's political and social transformation in the late 20th and early 21st century. While these wider developments have provided advantageous circumstances, the successful construction and institutionalisation of a new thriving academic field can only be explained by the strong personal commitment of key Taiwan scholars in Europe and the skilful integration of individual efforts through the creation of a Europe wide network.
\end{abstract}

Keywords: Taiwan, public diplomacy, Europe, area studies, institutionalisation 


\section{INTRODUCTION}

Taiwan Studies in Europe presents an intriguing case of a new area study. It started to emerge in the 1990 with a few individual academic projects focusing on the island. Since then Taiwan Studies has rapidly grown into a thriving field in Europe. There are now academic centres across Europe, special university courses on Taiwan, a number of publication venues and a large annual meeting of Taiwan scholars from all over Europe. The Second World Congress of Taiwan Studies took place in Europe after the inaugural congress was held in Taiwan in 2012. Europe has also been a focal point of a recent initiative by the Center for Chinese Studies at National Central Library in Taiwan to establish so-called Taiwan Resource Centers for Chinese Studies to promote "Chinese culture with Taiwanese characteristics" abroad. So far, 11 centres have been established in Europe, more than in any other region of the world (Taiwan Resource Center for Chinese Studies 2016). The quick expansion of Taiwan Studies in Europe and the high profile of European Taiwan Studies in the global field are in many ways surprising. First of all, there were few institutional foundations to build on when the field was first set up. It started to emerge as a new field at a time when the area studies model had come under serious criticism and discussion in academia (Cumings 1999; Diamond 1992; Pheng 2008). Unlike Japan or the US, Europe did not have extensive colonial involvement in Taiwan or military commitments in the Taiwan Strait which might have motivated academic interest in the island. Taiwanese overseas have been an important driving force for Taiwan Studies outside Taiwan. In Europe, however, the Taiwanese diaspora is relatively small and weak compared to that of other regions such as the United States (Lang 2015: 17). The question therefore arises how we can explain the emergence of Taiwan Studies in Europe and its increasing importance in the global field of Taiwan Studies.

Most studies of the field of Taiwan Studies have focused on the academic context in Taiwan or the US. Shelley Rigger (2002/2003) has described Taiwan Studies as a sustainable but marginalised subfield. Similarly, Cheng and Marble (2004) have looked at Taiwan Studies in its integration with the social sciences (Cheng and Marble 2004). In his review of scholarship on Taiwan, Murray Rubinstein (2013) describes Taiwan Studies as a multidisciplinary sub-field that has undergone multiple transformations over time. He concludes his paper by looking back at his keynote speech to the 2009 European Association of Taiwan Studies (EATS) conference in Madrid, where he raised the question "Is Taiwan Studies dead?," referring to the closure of important Taiwan Studies institutions in the US and the shift of leading experts away from Taiwan Studies towards research on the People's Republic of China. 
In a response to Rubinstein's 2009 keynote speech, Jonathan Sullivan (2011) has argued that in terms of research output, Taiwan Studies is neither dead, nor marginalised, but rather fractionalised as research tends to be distributed across a wide range of lower-ranking journals.

This paper suggests a different perspective on Taiwan Studies by arguing that in the European context, Taiwan Studies has been steadily growing and expanding without getting fragmented. Local politics and government agencies in Taiwan have been an important driving force for the construction of a new area study "Taiwan Studies" overseas. In that sense, the evolution of Taiwan Studies in Europe "reverses" the traditional model of area studies as externally imposed framings of knowledge on a region (Ohlendorf 2012). A key feature of European Taiwan Studies has been the deliberate effort to institutionalise the academic field. Huntington (1968) has defined institutionalisation as the "process by which organisations and procedures acquire value and stability" (12). Institutionalisation thus goes beyond mere stability or the ability to endure. It also implies the concept of value-infusion through which organisations become meaningful in and of themselves to those involved (Selznick 1957: 17). While value-infusion is hard to measure or quantify, it reminds us of the need to look at Taiwan Studies not just in terms of numbers (of years, institutes, conferences, staff, publications, etc.), but also in terms of conceptualisations and framings. This study therefore seeks to not only analyse factors for the visible emergence and expansion of Taiwan Studies in Europe but also to look at the ways the academic field has been conceptualised and legitimised in different academic contexts. An overview of selected Taiwan Studies institutions shows that the conceptualisations of Taiwan Studies are quite diverse and not monolithic. The diversity of Taiwan Studies in Europe has been complemented by the integrating dynamics of a Europe-wide network.

\section{THE TRADITION OF ASIAN STUDIES IN EUROPE}

The history of Asian Studies in Europe partly explains why there was room for a new area study to emerge and why it was not so much associated with the controversies affecting the area study model particularly in the academic context of the US. In the European context, studies of contemporary Asia in the form of area studies are a relatively recent phenomenon. However, they build on older traditions of Oriental Studies at European universities. Missionaries produced first systematic bodies of knowledge on Asia (Lach 1965: 314-331). During the age of imperialism, European studies of Asia significantly expanded. 
Yet as European powers were confronted with very different circumstances in Asia, the institutionalisation of Asian studies was never monolithic. Britain, for instance, still dominates in social science scholarship on India and China. Other cases challenge the direct connection between imperialist expansion in Asia and domestic interest in Oriental studies. Sweden, for instance, never possessed any colonies in Asia but set up Oriental Studies at universities early on. Spain, in contrast, did not institutionalise Asian Studies until the late 20th century (Folch 1995: 149). Fascination with the "Orient" was also triggered by domestic social changes: "Western disillusion with its own self produced the reaction of romanticism, with its renewed emphasis on nostalgia for the rustic antique; a nostalgia that increased as industrialism changed the face of Europe. It provided a new rationale for interest in the unchanging Orient" (Sardar 1999: 41).

At European universities, Asian Studies were first framed along civilisational, philological lines. The first chairs for Sinology were set up in Paris in 1814 and in Oxford in 1876. Chairs for Indology were founded in Paris, Bonn and Oxford during the first half of the 19th century. During the early second half of the 19th century, Leiden and Paris set up chairs in Japanology. Oriental studies were seen as elitist scholarship, conducted within the ivory tower of academia, "a purely disinterested study of oriental cultures for their own sakes somewhat on a par with the study of classical antiquity" (Gibb 1963: 9). There are exceptions to the general emphasis on philology and cultural studies. For instance, institutions like the School of Oriental and African Studies in London with its founding motto "Knowledge is Power" clearly served to train colonial administrators and facilitate imperial control (Brown 2016: 239). However, at European universities, the emphasis on cultural studies and ancient civilisations of Asia remained at the centre of Oriental Studies.

While Europe dominated the Asian Studies field in the 19th and early 20th century, from the mid-20th century onwards, the gravitational centre of Asian Studies scholarship moved to the United States. Already during the Nazi period, many eminent Asian scholars in Europe were forced to flee from the continent, which seriously weakened particularly German universities (Kern 1998: 511). Many of those European experts relocated to the United States. The brain drain from Europe to the United States continued after the Second World War. Partly this had to do with the new opportunities for academics in the United States. At US universities, the field of Asian Studies benefitted from a boom in Asian area studies in the context of the Cold War. Seeking to contain the expansion of communism in the region, the US government invested 
enormous sums of money in the creation of new area studies programmes at North American universities and the training of Asian Studies specialists. The study of politics, international relations, history and anthropology formed the core of the new area studies programmes while humanities and classical studies played a secondary role (Song 2013: 401).

Meanwhile, in Europe, interest in Asian affairs significantly decreased as many former colonies gained independence from Europe. After the destruction of the Second World War, European states concentrated on rebuilding their countries within a larger European framework. The economic and social recovery of Western Europe relied on the protection and intervention by the US. The Europe-US relationship became a key concern and further diverted attention away from Asia. As European governments started to focus on the Atlantic relationship, government funding for Asian Studies shrank. While the changed settings in Asia stimulated a new model of Asian Studies scholarship in the form of area studies at US universities, European universities by and large continued the older tradition of philology-based studies of Asia. Attempts to reform the Asian Studies field in Europe largely relied on US recommendations (Hayter 1975: 170). Yet given that funding was limited and public interest centred on Europe and its relationship with the US, there was not much space for institutional reform or realignment of Asian Studies in Europe.

As a result, modern Asian Studies in the US clearly overshadowed the field in Europe in the postwar period. However, the marginal position of European Asian Studies during the Cold War period has meant that Asian Studies in Europe have remained relatively unscathed by the big area studies debates of the 1990s. US area studies have been confronted with serious charges regarding their involvement in US policy on Asia during the Cold War. In the 1990s, this debate broadened and challenged the area studies model not just due to the alleged political complicity of area studies in the past but also due to their epistemological foundations as area-based fields of scholarship in an age of globalisation (Szanton 2004: 19-20). European Asian Studies have not remained free from criticism, as is exemplified by Edward Said's (1979) attack on European Orientalist scholarship in the context of imperialism. Yet the relatively long tradition and philological orientation of European Asian studies combined with their marginal position during the second half of the twentieth century have resulted in less heated discussions compared to the US and a generally more positive attitude towards area-based scholarship also in the contemporary period (Scharping 2001: 1). 
European interest in Asia has been revived in the post-Cold War period. After the breakdown of the Soviet bloc, European integration accelerated and intensified. The European Union was established in 1993, and the Euro was introduced in 1999. As European integration has deepened, Europe has become less concerned about the Atlantic relationship and increasingly paid attention to Asia for economic and strategic reasons. Especially China's potential as a rising power has captured the European imagination. Europe's relations with China are unrestricted by the complex and important relationship the US has with Taiwan (Gill and Murphy 2008: 9). Since 1996, representatives of Asian and European countries have come together in the annual Asia-Europe Meetings (ASEM) to engage in dialogue and cooperation (Robles 2008: 2829). European countries have also set up new research institutes and think tanks specialising on Asian affairs.

At European universities, Asian Studies departments have shifted towards more contemporary studies of Asia, introducing the US model of area studies. However, Asian Studies have been impacted by shrinking public funding for universities in Europe (Osiander 2001: 32). While national governments have kept an important regulatory role in providing and controlling access to higher education, the dominant discourse on higher education has shifted from emphasising the university's mandate as serving the needs of the state and the nation towards an understanding of the university as serving global goals of development. Those discourses of "the global" are closely linked to new recommendations that emphasise the introduction of market mechanisms and internationalisation as strategies for global competitiveness (Buckner 2016: 14). As financial support by governments has shrunk, universities have increasingly looked at alternative sources of funding. In this situation, wealthy East Asian governments and foundations have stepped in to aid the development of Asian Studies in Europe. This has provided an important opportunity for Taiwan Studies.

\section{TAIWAN'S ACADEMIC DIPLOMACY IN EUROPE}

It is important to keep the historical circumstances in mind when tracing the development of European Taiwan Studies. In the US, Taiwan Studies emerged at a time, when Taiwan had experienced decades of remarkable economic growth but was still ruled by an authoritarian regime and under the conditions of martial law, which limited its appeal to Western academics (Ohlendorf 2013). By the time Taiwan Studies evolved in Europe, however, the island was right 
in the middle of a political transformation and moving towards a democratic system. Interest in the island and attempts to strengthen systematic research on Taiwan did not raise many concerns in Europe at a time when Taiwan was already widely admired for its democratic achievements. Taiwan's democratic reforms of the late 1980s and early 1990s contrasted sharply from Beijing's crackdown of the 1989 student protests in Beijing (Cabestan 2008: 87).

Taiwan's democratic transition became a key argument in the Taiwanese government's effort to gain broader support for the island (Rawnsley 2003). Adopting a so-called "pragmatic, flexible diplomacy," the Taiwanese government under Lee Teng-hui gave up the one-China principle in its foreign relations. In its diplomacy, Taiwan started to focus on "substantive," semiofficial relations with other countries and thus tried to avoid the contested issue of de-iure sovereignty. Taiwan actively used its strength as a major aid donor, investor and trading power to foster stronger semi-official ties with other countries. Later on, the government also actively played on its appeal as a young democracy to gather support in the West. Support for academic research formed a very important part of this new pragmatic diplomacy. The political aspect of Taiwan's sponsorship of academic projects abroad becomes clear in the fact that in many cases they were not sponsored by the Taiwan Ministry of Education but the Ministry of Foreign Affairs.

Apart from the official government organisations, the most important funding body for Taiwan Studies in Europe has been the Chiang Ching-kuo Foundation for International Scholarly Exchange (CCKF). It was officially established in 1989 with the mission to support cultural exchange and academic research worldwide. Officially, the foundation operates as a private organisation, however, besides academics and business representatives, government officials hold important posts in the governing body of the CCKF (Wang Ailing, then Vice-President of the Chiang Ching-kuo Foundation, personal communication, 2008). The CCKF set up its first European headquarter in Prague in the Czech Republic in 1997. The choice of Prague reflected wider developments in EUTaiwan relations: after the collapse of the Socialist Bloc and the dissolution of the Soviet Union, Taiwan put a lot of hope in the newly independent and in some cases democratising Eastern European countries. Eastern Europe's need for foreign investments and financial support as well as wide-spread anticommunist sentiment seemed to provide a historical opportunity to further Taiwan's relations with those countries and to challenge the strong historical ties between the formerly Socialist Europe and the People's Republic of China (Tubilewicz 2007: 20-21). Ultimately, Taiwan failed to establish official diplomatic relations, but it secured "substantive" ties with many Central and 
Eastern European countries. Among them, the Czech Republic became one of Taiwan's most vocal supporters. In 1995, Prague was the first European capital to officially receive the Taiwanese premier Lien Chan. Since 1994, the Czech Republic has also officially supported Taiwan's plea for membership in the United Nations (Tubilewicz 2002: 32).

Even before the establishment of the CCKF overseas branch in Prague, the foundation got involved in funding European research projects. In the beginning, the CCFK mainly supported projects related to Sinology or Chinese Studies. However, in the course of the 1990s, the emphasis started to change and more and more funding was also given to research on Taiwan-related topics. Initially, support mainly covered individual specific research plans on Taiwan. However, increasingly the foundation has aimed at strengthening institutional foundations for Taiwan research in Europe. For instance, in 1999, Bochum University received a grant for a specialised Research Unit on Taiwanese Culture and Literature. By now, the CCKF has become the key supporter for the European Association of Taiwan Studies. The shift towards more Taiwan-related funding initiatives reflected changes in Taiwan's domestic environment, where the dominant China-centred paradigm characteristic of the authoritarian period got gradually replaced by more Taiwan-centred approaches in the 1990s (Chang 2009: 48).

The close links between Taiwan's public diplomacy and support for academic programmes become even clearer in the fact that it was Taiwan's Ministry of Foreign Affairs, which sponsored the first programme specialising in "Taiwan Studies" in Europe. Through its London representative office, Taiwan's government approached the School of Oriental and African Studies (SOAS) in London and offered financial support for a new special academic project on Taiwan. In 1999, the new Taiwan Studies Programme was launched at SOAS. One reason why Taiwan's Ministry of Foreign Affairs decided to approach SOAS may have been its long history of area studies. As a languageoriented field of study, comparable to Sinology, Taiwan Studies would have shared a lot with the field of Chinese Studies, which would have reduced the visibility of Taiwan compared to China in the academic context. However, raising Taiwan's international profile has been one of the key objectives of the Taiwan government in its public diplomacy. With its strong regional focus, SOAS provided an environment where Taiwan could relatively easily be set up as a new area study. As mentioned earlier, the area studies debates in the 1990s mainly targeted and affected area studies programmes in the US. In the European context, the area studies model remained relatively unscathed by the controversies. More concretely, in the case of Taiwan Studies, the absence 
of institutional predecessors meant that the emerging area study did not have to deal with a historical legacy. At the same time, it could take advantage of the existing academic expertise and institutional frameworks in the US. For instance, the SOAS Taiwan Studies programme first invited a US researcher, who studied the history of the Kuomintang (KMT) in Taiwan, to become a postdoctoral fellow at the programme. Prior to her appointment at SOAS, Megan Greene had been a member of the Taiwan Studies Workshop at Harvard University (Megan Greene, former SOAS Taiwan Studies postdoctoral fellow, personal communication, 2008). She brought academic expertise necessary for the teaching and research elements of the programme (Robert Ash, personal communication, 2010). The Taiwan Studies Programme at SOAS has been highlighted here because it created the first institutional platform of "Taiwan Studies" in Europe. The availability of funding from Taiwan sent a strong signal to Taiwan Studies networks in Europe and created incentives for the institutionalisation of the field. The first sections of this paper have mainly addressed the wider settings for Asian studies in Europe and social and political factors influencing the construction of Taiwan Studies as a new academic field. The second part of this paper looks in more detailed ways at European Taiwan Studies on national levels to show the distinct networks that have evolved but also to demonstrate that these networks occupy positions in a larger evolving field of European Taiwan Studies.

\section{TAIWAN STUDIES IN THE UNITED KINGDOM}

When the Taiwanese government and SOAS first agreed on setting up a new academic programme, they did not lay out any details. There was no clear blueprint. Raising Taiwan's profile was a key concern for the Taiwanese government, but in terms of academic frameworks and directions, the development of the programmed depended on the academics involved. The first funding period covered only three years. However, right from the beginning, the founder and first director of the Taiwan Studies Programme, Robert Ash, worked on establishing Taiwan Studies as a new field of research in its own right. As he put it in an interview, "I made that point very strongly in the beginning: We were not introducing Taiwan Studies at the school as an adjunct to Chinese Studies. We were not just interested in Taiwan in the context of security reasons or cross-Strait relations. Just as interesting as to look at the development of China since 1949 was it to look at the development of Taiwan since 1949" (Robert Ash, personal communication, 2010). Robert 
Ash was motivated by his personal viewpoint on scholarship when he designed the programme: "I'm a great advocate and defender of area studies, and back in 1999, I would have said: Yes, this is a new area study initiative." At the same time, the Taiwan Studies Programme was framed in a way that would also make it relevant to other disciplines. By putting emphasis on Taiwan's social, political and economic transformations since 1949, the Taiwan Studies Programme also highlighted Taiwan's significance as an important model or case study for comparative research. As it says on the website of the Centre of Taiwan Studies, "Analysis of the development experience of contemporary Taiwan serves to highlight a unique, but transferable model of economic growth, social transformation and political modernisation" (MA Taiwan Studies at SOAS, https://www.soas.ac.uk/taiwanstudies/mataiwanstudies/ [3 July 2016]).

The personal commitment of individual academics has been a decisive factor in the successful institutionalisation of the Taiwan Studies Programme. This becomes clear not only in the way Robert Ash's conceptualisation shaped the evolving programme but also in its quick expansion and growth after Dafydd Fell joined in 2003. Between 2002 and 2005, the Taiwanese government had actually reduced funding for the programme due to the economic situation in Taiwan at that time, yet the institutionalisation of the programme actually started to accelerate during those years, when Dafydd Fell took on his new position at SOAS first as postdoctoral fellow and later as deputy director and director of the centre (Robert Ash, personal communication, 2010). In 2006, the programme was officially turned into a full Centre of Taiwan Studies, which belongs to the Faculty of Law and Social Sciences at SOAS. There are regular seminar series, conferences and summer schools. By now students can take a full masters degree in Taiwan Studies, a range of both postgraduate and undergraduate courses is offered also to students from other degree programmes. Dayfdd Fell has not only played a crucial role in pushing forward the institutionalisation of Taiwan Studies at SOAS, he has also been a key figure in the development of Taiwan Studies on a European level. Among other contributions, he is the editor of the Routledge Research on Taiwan Series (Routledge Research on Taiwan Series 2016).

According to Fell, the emphasis on teaching at both undergraduate and postgraduate level has helped maintain a very distinct profile for the SOAS centre, even after other Taiwan Studies institutions have sprung up in Europe: "We have always felt that this [the teaching programme] is one of our great selling points, that we can do what nobody else can do. It is generally the format that the Taiwan Studies Centre will focus on running the academic 
events. In terms of courses, it is really rare in Europe" (Dafydd Fell, personal communication, 2009). In 2008, the SOAS Centre of Taiwan Studies received the 25,000 Euro Prize of the French Taiwanese Cultural Association for its achievements and contributions to the cultural exchange between Taiwan and Europe.

The launch of a Taiwan Studies Programme at SOAS has been a crucial factor for the successful institutionalisation of Taiwan Studies in Europe for various reasons: First of all, the SOAS Centre of Taiwan Studies (formerly Taiwan Studies Programme) created a first major framework and base for academics working on Taiwan individually throughout Europe. As an official institution with the term "Taiwan Studies" in its title, the SOAS programme gave legitimacy and first symbolic recognition to the emerging field. Through regular seminars, workshops and conferences, the centre brought together academics from various institutions and countries and thus helped build a new community of Taiwan Studies scholars not just in London but also in Europe, not least through its strong links to the EATS, which held its inaugural conference at SOAS in 2004. Headed by Dafydd Fell, the Centre of Taiwan Studies at SOAS is certainly the most active institution of Taiwan Studies in Europe.

However, SOAS has not remained the only institution in London where Taiwan Studies have developed. Just a few miles away, there is a Taiwan Research Programme affiliated with the Asia Research Centre of the London School of Economics and Political Science. It may seem surprising that two programmes have been institutionalised in the same city, engaging in similar fields of study. A closer look at the development of the two institutions shows that they have developed in close interaction with each other, resulting in what could be termed coordinated competition within the evolving academic field.

The history of the Taiwan Research Programme at the LSE can be traced back to a special grant awarded to Stephen Feuchtwang in 2000. The grant came from the Taiwan Representative Office in London and was meant to support a one year seminar series on Taiwan. Feuchtwang was also the head of the British Association of Chinese Studies at the time. Initially, the seminars formed part of the London China Seminar. Later on, in 2002, the London China Seminar was renamed London Taiwan Seminar (Shih Fanglong, personal communication, 2010). In the beginning, an outside observer would probably not have perceived the SOAS Taiwan Studies Programme and the London Taiwan Seminar as two very different projects. During the first years, most of the events of the London Taiwan Seminar were chaired by London School of Economics (LSE) faculty but hosted by SOAS. There was 
also a lot of overlap in terms of speakers and audiences, given that the Taiwan Studies community in London and Europe was still very small and emerging. Some of the speakers in the LSE chaired seminars were SOAS academics, and likewise, events organised by the Taiwan Studies Programme often featured Taiwan scholars from the LSE.

However, as the SOAS Taiwan Studies Programme was developing a clearer profile, the group organising the London Taiwan Seminar also took on a more distinct position in the field. To some of them, the appointment of a political scientist as the second postdoctoral fellow of the Taiwan Studies Programme signalled that the SOAS project was moving towards a social science based approach to Taiwan Studies (Shih Fang-long, personal communication 2010). In response, the organisers of the London Taiwan Seminar started to place more emphasis on cultural approaches to the study of Taiwan, which also reflected their personal academic backgrounds in anthropology and religious studies. The clearer focus on culture also became evident in the new name of their expanding project, which was renamed "Taiwan Culture Research Programme" and got affiliated with the Asia Research Centre at LSE. The culture-based approach informed not only the study of Taiwan at the Taiwan Culture Research Programme but also constituted very much the identity and profile of the programme itself as a distinct institution of Taiwan Studies in London. The organisers of the LSE Taiwan Culture Research Programme therefore perceived it as a real challenge when they saw SOAS moving into more culture-oriented seminars and events (Shih Fang-long, personal communication, 2010). They reacted with a basic repositioning of the LSE programme in 2008. Instead of highlighting culture, the LSE programme reinvented itself as the Taiwan Research Programme and emphasised its comparative approach to research on Taiwan. Since 2007, it has published the e-journal Taiwan in Comparative Perspective.

As an influential institution of broadly framed Taiwan Studies, the SOAS centre attracts a lot of academics working on Taiwan primarily. The LSE programme has tapped into new networks by organising topical events that bring together theorists and Taiwan expert or by integrating Taiwan into broader regional comparisons. For instance, the workshop "Taiwan and Justice in Comparative Perspective" included papers on the general themes of justice and policing as well as studies of the concept of justice in specific regional contexts including Taiwan but also Hong Kong, the PRC, Germany and the United Kingdom. Conceptually similar to Chen Kuanhsing's approach 
of "Asia as Method" (Chen 2010), the Taiwan Research Programme sees potential in Taiwan research to act as a methodological and theoretical tool that may help overcome the current conditions of dominant knowledge production and generate new academic positions and perspectives (London School of Economics 2015). Combined with the stronger emphasis on cultural studies approaches to themes like globalisation and localisation, the LSE Programme legitimises the study of Taiwan slightly differently compared to the Taiwan Studies Centre at SOAS, which besides the construction of Taiwan Studies as a new area study, highlights Taiwan's significance as a paradigm in the social sciences. The fact that two now largely independent "schools" of Taiwan Studies have evolved in the same city demonstrates how the little defined nature of the field has given rise to very different and distinct interpretations of the subject of Taiwan in academia within just a few years.

Another very important Taiwan Studies Programme in the UK is hosted by the China Policy Institute at the University of Nottingham. Under the directorship of Jonathan Sullivan, the programme in Nottingham hosts high profile seminars and lecture series, organises an annual conference and provides fellowships for $\mathrm{PhD}$ students specialising on Taiwan. Jonathan Sullivan has also very actively raised the profile of Taiwan Studies in online media. During the 2012 and 2016 presidential elections in Taiwan, he set up specialised blogspots for Taiwan scholars to share their research and insights on Taiwan. The China Policy Blog of the institute in Nottingham also has a special category for Taiwan-related contributions (China Policy Institute 2016).

St. Antony's College in Oxford has organised Taiwan Studies events for many years. The Taiwan Studies Programme cooperates with Taiwan's Taiwan Academy to hold seminars, lecture series and annual conferences on Taiwan. Since 2013, they have also introduced an optional postgraduate course on Cross-Strait Relations as part of the MA Contemporary China (University of Oxford 2016).

There are not many Taiwan Studies institutions in Europe. But as the comparison of different Taiwan Studies on the national and European level shows, the field has been institutionalised and conceptualised in very different ways, which has to do with the diversity of academic settings in European countries, personal professional identities of key scholars involved, and efforts to build a distinct profile and position within the wider emerging field of European Taiwan Studies. 


\section{TAIWAN STUDIES IN FRANCE}

France has a special position in Taiwan due to its Taipei office of the French Centre for Research on Contemporary China (CEFC). Initially, the CEFC was set up as a French research institute in Hong Kong in 1992, but since 1994, it has also had a second office in Taipei. The CEFC is funded by the French Ministry of Foreign Affairs and International Development (MAEDI) and the French National Centre for Scientific Research (Centre National de la Recherche Scientifique, CNRS). The opening of the Taipei office of the CEFC can be seen in the historical context of France-Taiwan and France-China relations. Paris was one of the first governments to diplomatically recognise Beijing in 1964. Both countries had concerns about a bipolar world and shared a desire to become strong independent world powers (Wellons 1994). After the Tiananmen Massacre in 1989 and the collapse of the Soviet Union, the situation changed. In the early 1990s, the France-PRC relationship became strained when France agreed on large arms sales to Taiwan in 1991 and 1992 (Casarina 2009: 35). In response, the Chinese authorities ordered the Paris government to temporarily close the French Consulate in Guangzhou in the following year (Rees 2009: 36). While the CNRS maintained its funding for educational relations with the People's Republic of China, the French Ministry of Foreign Affairs reduced its China budget from 50 million francs to circa 30 million francs in the early 1990s (Bullock 1993: 620).

The Taipei office of the CEFC has functioned as an important academic contact point between France and Taiwan. For instance, one of the first pioneers of Taiwan Studies in Europe, Fiorella Allio, held the directorship of the CEFC from 1998 to 2003. During her time as director, she actively built on her extensive contacts with Taiwanese researchers to foster links between Taiwan and France and help integrate the CEFC within the academic circles of Academia Sinica, where the CEFC Taipei office is located. In 2014, the well-known Taiwan expert Stéphane Corcuff assumed the directorship of the CEFC. Corcuff has been a key figure in the development of European Taiwan Studies both on the national level in France and the European level. His appointment as director of the CEFC has thus added great momentum to the wider development of Taiwan Studies and the intensified cooperation between Taiwanese researchers and international academics. Through its interdisciplinary journal China Perspectives, the CEFC circulates new research findings on Taiwan and China among the academic community. Taiwan topics often feature in the regular seminars and special workshops convened by the CEFC. The centre has also built a special collection of books, articles, proceedings and news reporting on Taiwan, China and Cross-Strait relations. 
At the university level, there are several instances of institutionalised Taiwan Studies. For instance, Jean Moulin University of Lyon III hosts the Taiwan Resource Center for Chinese Studies and offers courses on Taiwan film, history, culture, etc. In 1993, the CCKF supported the Institute of East Asian Studies in Lyon with funding to purchase a substantial amount of books published in Taiwan (Chung 2001). Teaching and events on Taiwan have been dependent on individual scholars' initiatives and interests in the field. The relatively strong centralism of the French political system has also influenced the academic field. Until recently, every new degree programme at a French university had to get approval from the French Ministry of Education. There were also strict national guidelines stipulating what kind of undergraduate and postgraduate programmes could be set up. Thus traditional disciplinary teaching has remained dominant in French academia and cases of interdisciplinary projects or entirely new disciplines are quite rare (Bowen and Bentaboulet 2002: 554-556). Even within the field of Chinese Studies, it has been challenging to strengthen and institutionalise Taiwan related research. France looks back at a very long and proud tradition of classical sinology. This explains the strong philological orientation of Chinese Studies in France (Bianco 1995: 509). Compared to the United Kingdom, the shift towards an area studies model occurred much later and was introduced with greater reluctance.

However, universities are not the only important actors in the French academic system. A significant part of the research is carried out in specialised research institutions. The most distinguished and influential of them is the CNRS. The CNRS has supported the French Research Group on Taiwan (FRGT) from 2006 to 2009. The FRGT was a network of scholars working on Taiwan in different parts of the country. French Taiwan Studies have also been institutionalised in the Francophone Association of Taiwan Studies (Association Francophone d'Études Taïwanaises 2016). Many Taiwan Studies programmes in Europe are mainly funded by the Taiwanese government. The French projects seem quite special in the way they have successfully secured funding from their own government.

In spite of bureaucratic obstacles, leading scholars in France have consciously worked on the institutionalisation of academic Taiwan Studies. This becomes also evident in the way Taiwan Studies is legitimised through conscious reflection on the academic value of the new research field with regard to the wider academic community. For instance, the FRGT characterised Taiwan as a "laboratory of identities where new forms of cultural belonging to the Chinese world and to a national Taiwanese identity are conceptualised and formed." According to the website of the research group, Taiwan's special 
circumstances can reveal new aspects of identity formation beyond the ethnic nationalist paradigm and thus be of relevance to the broader social sciences (University of Provence 2010).

A more recent article by Stéphane Corcuff (2012) suggests the anthropological concept of liminality as a way to conceive of Taiwan's geopolitical relation to China. Being a liminal space, Taiwan is not just a recipient of the discourses of the bigger entity, but is in itself an active producer of meaning in the relationship of the two. As Corcuff summarises, "geopolitical liminality here defines an asymmetric interdependence where the small entity has something to say in the couple formed with the bigger entity, thanks to the historical and cultural thickness of their geopolitical relation over time" (62).

\section{TAIWAN STUDIES IN GERMANY}

Germany has seen individual Taiwan Studies initiatives early on, but most of these projects developed relatively independently of each other and without strong coordination. This may not be surprising given the federal system of the state, which is also reflected in the structure of the academic field. One of the Taiwan Studies pioneers in Germany was the political scientist Jürgen Domes, who began to look at Taiwan in his research in the 1960s. By the late 1980s, he also frequently visited the Xiamen Institute of Taiwan Studies and engaged in academic discussions with Chinese professors working there (Chen Kong-li, personal communication, 2008). At Saarbrücken University, Jürgen Domes established a Research Unit for Chinese and East Asian Politics, which featured many Taiwan related topics.

In the beginning of the 1990s, the Chiang Ching-kuo Foundation funded a special research project of the Max-Planck Society titled "The Austronesian Arrival - Research Project to Study the Connections between Taiwan and the Papua New Guinean Populations of the Trobrianders and the Roro." The CCKF also sponsored a Distinguished Lectureship on Culture and Society in Contemporary Taiwan at the University of Heidelberg. The well-known Taiwanese writer Lung Ying-tai taught about Taiwanese literature of the Japanese colonial period (Chen 1994). Axel Schneider established a special Taiwan Study group, which compiled news, journal articles, monographs and online sources on the island. He also taught courses on Taiwan's economy and political transformation (Axel Schneider, personal communication, 2010). Other CCKF-supported projects on Taiwan included "The Other China" at the University of Munich and the "Twentieth Century Literary History Project" at Bochum University. 
Bochum became a very influential centre of Taiwan related research in Germany. The chair of the Department of Chinese Language and Literature at the university, Professor Helmut Martin, had a special interest in Taiwan literature and encouraged the translation of several Taiwanese works of the 20th century into German language (Henning Kloeter, personal communication, 2008). The emphasis on literature made it relatively easy to embed the new research area into the existing Department of Chinese Language and Literature. Taiwan research framed as studies on Taiwan literature and culture was much more in line with the philological orientation of Chinese Studies in Germany than a social science based area studies model would have been. Helmut Martin tried to raise Taiwan's profile in the German National Association of Chinese Studies. Shortly before he died in 1999, he formulated the theme of the annual meeting of the association as "China Studies: China and Taiwan in the Public Sphere? Paradigm Change in Media, Politics and Academia." One of the challenges of individual Taiwan Studies Projects in Germany has been the strong dependence on a few key individuals driving those initiatives. Very often Taiwan Studies activities quickly disintegrated once the person in charge passed away or moved to another institution. The early projects also emerged at a time when Taiwan Studies was still a contested concept domestically in Taiwan. A systematic effort of the Taiwanese government to support the institutionalisation of the field really only became visible with the establishment of the SOAS progamme carrying the title Taiwan Studies.

Nearly a decade later, in 2008, the political scientist and Greater China expert Gunter Schubert established a new Taiwan research institution in Tübingen under the name European Research Centre on Contemporary Taiwan (ERCCT). Other institutions of Taiwan Studies had already been set up both in Taiwan and Europe and been operating for a few years. For the ERCCT, Schubert could thus draw from the experience of other centres and also think about how to situate the ERCCT within the wider European context. Schubert got partly inspired by the Taiwan Research Center at National Chengchi University in Taiwan when he first developed the proposal for a new Taiwan Studies institution (Gunter Schubert, personal communication, 2007). On the ERCCT website, the centre is consciously positioned in the wider European academic field. As the ERCCT website states, "Taiwan studies in Europe must be promoted vigorously to become more present and institutionalised. Setting up specific Master's programmes, organising workshops, conferences and public lectures, and publishing academic papers on Taiwan-related issues are all good and necessary activities in this direction, but they are not enough. Equal attention has to be paid to the promotion of empirical research on Taiwan, 
especially at the $\mathrm{PhD}$ and postdoc levels. At the same time, postgraduate Taiwan studies should be more centralised in order to enable students to get as much research-related feedback as possible" (Eberhard Karls Universitat Tubingen 2009). The proposal suggests a differentiation of tasks on a European scale and specialisation of the centre as a hub for postgraduate research on Taiwan. The centre is jointly financed by the University of Tübingen and the CCKF for Scholarly Exchange. In 2014, it was selected as one of four Chiang Chingkuo Foundation Overseas Centers and has since carried the title European Research Center on Contemporary Taiwan - A CCK Foundation Overseas Center (CCKF-ERCCT).

\section{TAIWAN STUDIES IN OTHER EUROPEAN COUNTRIES}

Germany, France and the United Kingdom have been very influential countries in the construction of European Taiwan Studies, but they are not the only players in the field. There is a whole range of projects in other European countries. In Austria, for instance, a Center of Taiwan Studies was set up in 2009 with support from the Austrian Science Fund and the National Science Council of Taiwan (Astrid Lipinsky, personal communication, 2009). The Vienna Center of Taiwan Studies, managed by Astrid Lipinsky, has organised a range of conferences, lecture series, Taiwanese film nights, and teaching cooperation with Taiwan (Vienna Center for Taiwan Studies 2016).

The Taipei Economic and Cultural Office in Vienna (TECO) and the Taiwan Foundation for Democracy (TFD) have also supported a Taiwan Study Center at Ljubljana University in Slovenia (Taiwan Study Centre 2016). The director of the centre, Saša Istenič, has developed two accredited courses that focus on Taiwan and has also brought Taiwan-related lectures into other undergraduate and postgraduate courses offered at the University of Ljubljana as well as universities in Croatia. The centre has organised Taiwan-related lecture series, workshops, exhibitions, movie screenings, etc.

In the Czech Republic, the Chiang Ching-kuo International Sinological Centre in Prague has run lecture series on Taiwan with invited speakers from Taiwan. Táňa Dluhošová has promoted Taiwan Studies in the Czech Republic since the 2008 EATS conference was held in Prague. She taught Taiwanrelated courses in Charles and Masaryk Universities and organised a number of academic conferences. In 2011, she received the prize of the FrenchTaiwanese Cultural Foundation for promoting Taiwan Studies in Central and Eastern Europe. She is now a research fellow at the Oriental Institute of the 
Czech Academy of Sciences and current director of the newly set up Research Center of the Oriental Institute in Taiwan at Academia Sinica, which is an important step in the development of Czech-Taiwanese academic cooperation.

In 2013, the Centre of Asian Studies at Vyutautas Magnus University in Kaunas set up a new Taiwan Centre in cooperation with National Chengchi University in Taiwan and the Taipei Mission in the Republic of Latvia. The coordinator of the Taiwan Centre is Agnès Budriūnaitès. Besides raising awareness and knowledge of Taiwanese culture and society in Lithuania, strengthening Taiwan-related resources at the Taiwan Centre and pursuing international collaborations in Taiwan Studies, the website lists close academic relations between Lithuanian and Taiwanese institutions among its main aims (ASC Centre for Asian Studies 2016).

Most recently, in May 2016, a new Taiwan Studies Centre was established at the Institute of Middle and Far East Studies at Jagiellonian University in Kraków with support from the Taiwan Foundation for Democracy. The coordinator of the centre is Adina Zemanek. The online introduction to the project mentions Poland's democratic transition as an experience that should put Polish researchers in a very good position to examine Taiwan's political transformation from a military dictatorship into a democracy. The website further highlights European and Asian academic exchangeas one of the key goals in an increasingly transnational academic world (Taiwan Studies Centre of the Jagiellonian University 2016).

This brief overview of Taiwan Studies institutions in Europe is far from complete. There are many more academic initiatives and events related to Taiwan taking place. The purpose of presenting a few important institutions of Taiwan Studies is not so much to provide an exhaustive list but rather to show that there now is quite a variety of institutions in Europe, with very distinct profiles. The expansion of academic Taiwan Studies in Europe cannot be explained without taking into account the personal commitment and efforts of the individual Taiwan scholars involved. In this context, it is also important to mention those scholars that have initiated special projects on Taiwan that are not linked to a specific institution. For instance, MingYeh Rawnsley's workshops on Taiwanese film have taken place in various universities. Other key scholars like Stéphane Corcuff, Jens Damm and Ann Heylen have provided strong links between Europe and Taiwan through their institutional affiliations in Taiwan and their contributions to European projects from Europe as well as Taiwan. There are many highly active individuals and various research projects occurring at the same time. This situation could have easily led to fragmentation of the Taiwan Studies circles in Europe and 
resulted in a weak assembly of largely isolated small Taiwan Studies units in various countries. However, Taiwan Studies in Europe have developed a very effective mechanism to synergise Taiwan Studies activities through the creation of a Europe wide network of Taiwan Studies.

\section{THE EUROPEAN ASSOCIATION OF TAIWAN STUDIES (EATS)}

From early on, Taiwan Studies in Europe have worked on building networks and cooperation across Europe and to institutionalise those links through an official association of Taiwan Studies. In 2004, SOAS hosted the first European Conference of Taiwan Studies, funded by a grant from the Chiang Chingkuo Foundation. The first conference on a European level also marked the establishment of the European Association of Taiwan Studies (EATS). EATS has been partly inspired by the North American Taiwan Studies Association (NATSA), where some of the key figures in European Taiwan Studies such as Dafydd Fell, Ann Heylen and Stéphane Corcuff first met.

One of the main objectives particularly of the first conferences was to find out who was studying Taiwan in Europe and to bring those scholars together in a special Taiwan Studies meeting. Over the years, the EATS conferences have been held in different regions of Europe also with a view to broaden participation in European Taiwan Studies beyond the core countries of the United Kingdom, France and Germany. The host cities of EATS conferences include London, Bochum, Paris, Stockholm, Prague, Madrid, Ljubljana, Sønderborg, Lyon, Kraków, Portsmouth, and Venice (to be held in 2017). The organisers of EATS have steadily worked on strengthening the institutional basis of the association. Initially, EATS was administered by SOAS in London. At the Paris meeting in 2006, the association endorsed a constitution and elected an Executive Board. Since 2010, the association has been operating as an independent association registered in Tübingen. The biannual EATS Newsletter, edited by Ming-Yeh Rawnsley, further contributes to the strengthening of the EATS network. European Taiwan Studies have also become more visible in terms of publications. Several EATS conferences have resulted in special journal issues and edited volumes. There is now also a major new book publishing venue for research on Taiwan with the Routledge Research on Taiwan Series, edited by Dafydd Fell. In 2018, the publisher Brill will launch a new International Journal of Taiwan Studies with Ming-Yeh Rawnsley as the editor.

In addition, EATS has worked on cultivating a new generation of Taiwan Studies researchers. For instance, the organisers of the annual 
conferences have tried to maintain an approximate 50:50 balance between faculty members and $\mathrm{PhD}$ students (Fell 2013: 3). A special MA panel gives younger students an opportunity to present their dissertation research and get feedback from senior colleagues in the field. In addition, EATS has also been involved in a range of special events, e.g., the 2010 "Graduate Teaching Workshop: Historical Legacies of Taiwanese Culture" in Brno. Since 2011, EATS has also awarded the Young Scholars Award to the best conference papers by junior scholars. Since 2016, BA and MA students can submit their dissertations to be considered for the newly launched EATS/MOFA Taiwan Studies Dissertation Award, which is supported by the Taiwan Ministry of Foreign Affairs.

\section{CONCLUSION}

Compared to other parts of the world, academic Taiwan Studies have evolved relatively late in Europe at a time when Taiwan actively embarked on academic diplomacy to gain international support. Taiwan Studies as a field has been actively promoted and coordinated by individual scholars who could build on experience gained in Taiwan Studies institutions in the US. The diversity contained within the entity of Europe is reflected in the variety of Taiwan Studies institutions. A key element to the successful institutionalisation of Taiwan Studies has been the creation of a Europe wide network as it has allowed European Taiwan Studies to allocate resources and facilitate exchange. By now, Europe has become one of the most vibrant sites of academic Taiwan Studies.

However, the quick expansion of the academic field of Taiwan Studies might also imply a potential weakness. The more extensive the institutional infrastructure has become, the more the question arises what ultimately legitimises this new academic field. To an outsider, European Taiwan Studies might simply appear to be an insular, self-referential academic network. This risk is enhanced by the fact that Taiwan Studies continue to depend on funding from Taiwan. As a liberal democracy, Taiwan is relatively well positioned to support academic research in European countries whose political values it shares. The strong support from Taiwan for academic studies in Europe also ensures close connections between scholars based in Europe and the area that they study through academic exchange, visiting lectureships, collaborative grants, etc. Still, particular financial resources enable certain questions to be posed, while others can be ignored. Therefore, there is an inherent incentive to diversify sources of funding. 
Given that the institutionalisation of Taiwan Studies has been pursued so deliberately, it may be necessary to make assumptions and expectations of the theoretical conceptualisations of the expanding field more explicit. Individual Taiwan Studies institutions and scholars in Europe have already developed very interesting conceptualisations of the field, which could probably be broadened. One way of making the field relevant to those outside the Taiwan Studies circles is through publications that have gone through peer review and that can reach a wider audience. The EATS has put a lot of emphasis on this aspect and launched an extensive research project on compiling a comprehensive list of publications resulting from EATS conferences.

Stronger dialogue with other disciplines could be reached by more topical projects where non-Taiwan experts from the established disciplines collaborate with those specialising on Taiwan. Similarly, cross-regional works and comparisons could help to foster exchange between those working on Taiwan and those studying other regions in the world. There are already very interesting projects taking place such as the e-journal Taiwan in Comparative Perspective or the EATS conference on Taiwan and Its Neighbours in 2013, and there seems to be room to expand those activities.

\section{NOTES}

* Hardina Ohlendorf is a lecturer in the Social Science Division of Mahidol University International College (MUIC), Thailand, and a Research Associate at the Centre of Taiwan Studies, School of Oriental and African Studies (SOAS), University of London. She received her $\mathrm{PhD}$ in Political Science from SOAS, University of London. Prior to moving to Thailand, she worked as a Senior Teaching Fellow in the Politics of China at SOAS and was a visiting scholar at the Institute of Sociology, Academia Sinica, with the Taiwan Fellowship. In her research, she looks at the politics of area studies, cultural and political aspects of Cross-Strait tourism, and Chinese identities in Southeast Asia. Her publications include "The Taiwan Dilemma in Chinese Nationalism: Taiwan Studies in the People's Republic of China," Asian Survey, 2014, Vol. 54 (3), 471-491. The research for this paper was funded by the Research Grant for Foreign Scholars in Chinese Studies and the Taiwan Fellowship of the Taiwan Ministry of Foreign Affairs. An early version of this paper was first presented at the First World Congress of Taiwan Studies, Academia Sinica, 26-28 April 2012. Hardina Ohlendorf would like to thank the anonymous reviewers of this article for their constructive comments. 


\section{REFERENCES}

Association Francophone d'Études Taïwanaises. 2015. http://www.etudes-taiwanaises.fr/ (accessed 15 September 2016).

ASC Centre for Asian Studies. 2016. Taiwan Centre. http://asc.vdu.lt/taiwan-centre/ (accessed on 29 November 2016).

Bianco, L. 1995. French Studies of contemporary China. China Quarterly 142: 509-520, https://doi.org/10.1017/S0305741000035037.

Bowen, J. R. and Bentaboulet, M. 2002. On the institutionalization of the social and human sciences in France. Anthropological Quarterly 75: 537-556, https://doi.org/10.1353/ anq.2002.0043.

Brown, I. 2016. The School of Oriental and African Studies: Imperial training and the expansion of learning. Cambridge: Cambridge University Press, https://doi. org/10.1017/CBO9781316687208.

Buckner, E. S. 2016. The changing discourse on higher education and the nation-state, 1960-2010. Higher Education, https://doi.org/10.1007/s10734-016-0056-2.

Bullock, M. B. 1993. The effects of Tiananmen on China's international scientific and educational cooperation. In China's economic dilemmas in the 1990s: The problems of reforms, modernization and interdependence, ed. Joint Economic Committee, Congress of the United States, 611-628. New York: M. E. Sharpe.

Cabestan, J. P. 2008. The Taiwan issue in Europe-China relations: An irritant more than leverage. In China-Europe relations: Perceptions, policies, and prospects, ed. Shambaugh, D., Sandschneider, E. and Hong, Z., 84-102. Abingdon and New York: Routledge.

Casarina, N. 2009. Remaking global order: The evolution of Europe-China relations and its implications for East Asia and the United States. Oxford: Oxford University Press, https://doi.org/10.1093/acprof:oso/9780199560073.001.0001.

Chang, B.-Y. 2009. The cultural turn and Taiwan identity in the 1990s. In Cultural discourse in Taiwan, ed. Chang, C.-C., Wang, I.-C. and Zepetnek, S. T. Kaohsiung: Center for the Humanities and Social Sciences and the College of Liberal Arts, National Sun Yat-sen University.

Chen, C.-K. 2010. Asia as method: Toward deimperialization. Durham: Duke University Press, https://doi.org/10.1215/9780822391692.

Chen, Y.-S. 1994. Taiwan Heute-Überblick über die Taiwanesische Literatur und Taiwanstudien in Deutschland, http://taiwanheute.nat.gov.tw/ ct.asp? xitem $=56182 \&$ ctnode $=1580 \& m p=22($ accessed 15 September 2016).

Cheng, T. J. and Marble, A. 2004. Taiwan Studies and the social sciences. Issues and Studies 40 (3/4): 9-57.

Chiang Ching-kuo Foundation. N.D. http://www.cckf.org/e-introduce.htm (accessed 27 March 2012).

China Policy Institute. 2016. Analysis. Category Taiwan. https://cpianalysis.org/category/ taiwan/ (accessed 30 November 2016).

Chung, O. 2001.Taiwan Heute - EuropasChinaforscher. http://taiwanheute.nat.gov.tw/ ct.asp?xItem $=43102 \&$ ctNode $=1555$ (accessed 30 November 2016). 
Corcuff, S. 2012. The liminality of Taiwan: A case-study in geopolitics. Taiwan in Comparative Perspective 4: 34-64.

Cumings, B. 1999. Boundary displacement: Area studies and international studies during and after the Cold War. In Universities and empire: Money and politics in the social sciences during the Cold War, ed. Simpson, C., 159-188. New York: New Press.

Diamond, S. 1992. Compromised campus: The collaboration of universities with the intelligence community, 1945-1955. New York: Oxford University Press.

Eberhard Karls Universitat Tubingen. 2009. Idea and concept of the European Research Centre on Taiwan http://www.ercct.uni-tuebingen.de/AdTXP/index.php?s=01About-ERCCT (accessed 28 March 2009).

Eden, D. 2000. Europe and the Atlantic relationship. In Europe and the Atlantic relationship: Issues of identity, security and power, ed. Eden, D., 1-12. New York: Palgrave Macmillan, https://doi.org/10.1007/978-0-333-97754-5_1.

European Research Centre for Contemporary China. 2009. About ERCCT. http://www. ercct.uni-tuebingen.de/AdTXP/index.php?s=01-About-ERCCT (accessed 28 March 2009).

Folch, D. 1995. Sinological materials in some Spanish libraries. In Europe Studies China: Papers from an International Conference on the History of European Sinology, ed. Caley, J. and Ming, W., 149-160. London: Han Shan Tang Books.

French Centre for Research on Contemporary China Newsletter. 2010. http://www.cefc. com.hk/francais/enewsletter/LettreAoutSept/Programme11bleu\%20copie.pdf (accessed 12 May 2010).

Gibb, H. 1963. Area studies reconsidered. London: School of Oriental and African Studies, University of London.

Gill, B. and Murphy, M. 2008. China-Europe relations: Implications and policy recommendations for the United States. A report of the CSIS Freeman Chair in Chinese Studies. Washington: Center for Strategic and International Studies.

Hayter, W. 1975. The Hayter Report and after. Oxford Review of Education 1: 169-172, https://doi.org/10.1080/0305498750010208.

Huntington, S. 1968. Political order in changing societies. New Haven and London: Yale University Press.

Kern, M. 1998. The emigration of German sinologists 1933-1945: Notes on the history and historiography of Chinese Studies. Journal of the American Oriental Society 118: 507-529, https://doi.org/10.2307/604784.

Lach, D. F. 1965. Asia in the Making of Europe, vol. 1. Chicago and London: University of Chicago Press.

Lang, B. 2015. Taiwanese lobbying in the European Union: 'Workable diplomacy' and its limitations. EU Diplomacy Paper 8/2015. College of Europe, Department of EU International Relations and Diplomacy Studies.

Lewis, B. 1994. Islam and the West. Oxford: Oxford University Press.

London China Seminar. 2012. http://dialspace.dial.pipex.com/town/lane/gax48/epage/ news_chinaseminar2.htm (accessed 21 March 2012).

London School of Economics. 2015. About this programme. http://www.lse.ac.uk/ collections/taiwanProgramme/aboutThisProgramme.htm (accessed 28 May 2015).

Ohlendorf, H. 2012. The construction of Taiwan identity in the global field of Taiwan Studies. PhD diss., SOAS, University of London, U.K. 
. 2013. Studying Taiwan: The politics of area studies in the United States and Europe. Paper presented at the conference on Framing Asian Studies: Geopolitics, Institutions, Networks, 18-20 November, Leiden, Netherlands.

Osiander, A. 2001. Settings for East Asian Studies in Europe and the USA: An explorative study. Hamburg: Institut für Asienkunde.

Pheng, C. 2008. Universal areas: Asian studies in a world of motion. In The postcolonial and the global, ed. Regathi, K. and Hawley, J. C., 54-86. Minneapolis: University of Minnesota Press.

Rawnsley, G. D. 2003. Selling democracy: Diplomacy, propaganda and democratisation in Taiwan. China Perspectives, No. 47. http://chinaperspectives.revues.org/361 (accessed 19 September 2019).

Rees, N. 2009. EU-China relations: Historical and contemporary perspectives. The European Union and China: Interests and dilemmas, ed. Taneja, P., Wiessala, G. and Wilson, J., 31-46. Amsterdam and New York: Editions Rodopi B. V.

Rigger, S. 2002/2003. Political science and Taiwan's domestic politics: The state of the field. Issues and Studies 38/39 (4/1): 49-92.

Robles, A. C. Jr. 2008. The Asia-Europe meeting: The theory and practice of interregionalism. Abingdon and New York: Routledge.

Routledge Research on Taiwan Series. 2016. https:/www.routledge.com/RoutledgeResearch-on-Taiwan-Series/book-series/RRTAIWAN (accessed 29 November 2016).

Rubinstein, M. 2013. Studying "Taiwan Studies": The evolution and the transformations of a multi-disciplinary sub-field, $1600 \mathrm{CE}$ to $2013 \mathrm{CE}$. https://aacs.ccny.cuny. edu/2013conference/Papers/Rubenstein\%20Murray_1.pdf (accessed 30 November 2016).

Said, E. 1979. Orientalism. New York: Vintage.

Sardar, Z. 1999. Orientalism. Buckingham and Philadelphia: Open University Press.

Scharping, T. 2001. Die sozialwissenschaftliche Chinaforschung. Rückblick und Ausblick. Kölner China-Studien (online). Arbeitspapiere zur Politik, Wirtschaft und Gesellschaft Ostasiens, www.phil-fak.uni-koeln.de/fileadmin/chinastudien/.../ No_2000-1.pdf (accessed 3 October 2016).

Selznick, P. 1957. Leadership in administration: A sociological interpretation. New York: Harper and Row.

Song, S.-J. 2013. Southeast Asian Studies in the U.S.: Construction of traditions of an autonomous history, its limitations, and future tasks. In The historical construction of Southeast Asian Studies: Korea and Beyond, ed. Park, S. W. and King, V., 399426. Singapore: ISEAS Publishing.

Sullivan, J. 2011. Is Taiwan Studies in decline? The China Quarterly 207: 706-718, https:// doi.org/10.1017/S0305741011000725.

Szanton, D. L. 2004. Introduction: The origin, nature and challenges of Area Studies in the United States. In The politics of knowledge: Area Studies and the disciplines, ed. Szanton, D. L., 1-33. Berkeley and Los Angeles: University of California Press.

Taipei Wirtschafts- und Kulturbüro Wien. N.D. http://culture.taipei.at/de/ (accessed 28 September 2010).

Taiwan Centre of the Centre of Asian Studies at Vyutautas Magnus University in Kaunas http://asc.vdu.lt/taiwan-centre/ (accessed 29 November 2016). 
Taiwan Resource Center for Chinese Studies. 2016. General introduction. http://trccs.ncl. edu.tw/e-about.aspx (accessed 30 November 2016)

Taiwan Research Programme at the London School of Economics and Political Science. 2010. http://www.lse.ac.uk/collections/taiwanProgramme/aboutThisProgramme. htm (accessed 28 May 2010).

Taiwan Studies Centre of the Jagiellonian University. 2016. About the project. http://www. taiwan.orient.uj.edu.pl/en_GB/projekt (accessed 30 November 2016).

Taiwan Study Centre at Ljubljana University. 2016. Taiwan Study Centre at Ljubljana University. http://www.tajvan.si (accessed 30 November 2016).

Tubilewicz, C. 2002. Affordable ally: Taiwan's diplomatic venture in Macedonia. Politics 22: 31-38, https://doi.org/10.1111/1467-9256.00156. . 2007. Taiwan and post-communist Europe: Shopping for allies. Abingdon and New York: Routledge.

University of Oxford. 2016. Taiwan Studies programme at St. Antony's College, University of Oxford. http://www.sant.ox.ac.uk/research-centres/taiwan-studies-programme (accessed 30 November 2016)

University of Provence. 2010. French research group on Taiwan. http://sites.univ-provence. $\mathrm{fr} / \mathrm{wmap} / \mathrm{map} / \mathrm{gdr}$ taiwan-programme.php (accessed 10 May 2010).

Vienna Center for Taiwan Studies. 2016. https://tsc.univie.ac.at/ (accessed 30 November 2016).

Wellons, P. 1994. Sino-French relations: Historical alliance vs. economic reality. Pacific Review 7 (3): 341-348, https://doi.org/10.1080/09512749408719102. 